\title{
Analysis of Characteristics of the Lightning around the Capsized “Oriental Star" Incident
}

\author{
Guoliang Li' ${ }^{1}$, Jun $\mathrm{Li}^{2}$, Xiang Li ${ }^{1}$, Ying Pi ${ }^{1}$ \\ ${ }^{1}$ Hubei Lightning Protection Center, Wuhan, China \\ ${ }^{2}$ Hubei Meteorological Information and Technical Support Center, Wuhan, China \\ Email: guoliang_li@163.com
}

How to cite this paper: Li, G.L., Li, J., Li, X. and Pi, Y. (2017) Analysis of Characteristics of the Lightning around the Capsized "Oriental Star” Incident. Open Access Library Journal, 4: e3801.

https://doi.org/10.4236/oalib.1103801

Received: July 3, 2017

Accepted: August 19, 2017

Published: August 22, 2017

Copyright $\odot 2017$ by authors and Open Access Library Inc.

This work is licensed under the Creative Commons Attribution International License (CC BY 4.0).

http://creativecommons.org/licenses/by/4.0/

\section{(c) (i) Open Access}

\begin{abstract}
For the study of characteristics of the lightning around the capsized "Oriental Star" incident, this paper analyzes the lightning space distribution in the surrounding, preliminary judging from characteristics of the lightning figure out the form of disastrous weather patterns. It is concluded that: the wreck accident happened in lightning highest frequency period, also most lightning frequency region, as well as the biggest negative rather than positive lightning current time bucket and region. The latest lightning is less than $300 \mathrm{~m}$ from the accident, leads to a higher possibility of damage to the ship communications equipment by lightning electromagnetic induction, which needs to further strengthen the safety precautions against ships during a thunderstorm.
\end{abstract}

\section{Subject Areas}

Atmospheric Sciences

\section{Keywords}

The Capsized “Oriental Star” Incident, Disastrous Weather, Lightning Space Distribution

\section{1. 引言}

湖北省年平均雷电日数为 $36 \mathrm{~d}$, 属中雷区, 鄂西南、鄂东地区年平均雷电 日数最多, 属多雷区。2015 年 6 月 1 2 日, 湖北南部发生了一次强对流天气 过程, 瞬时极大风力达 12 13 级, 1 小时降雨量达 $94.4 \mathrm{~mm}$, 监利县 1 小时闪 电达 1865 次, 虽然持续时间不足 2 天, 但强度之大确实罕见, 给国家生产和 人民的安全带来极大影响。重庆 “东方之星” 号客轮于 1 日 21 时 32 分在长 江翻沉, 地点在湖北省监利县长江大马洲水道 $\left(29.76189^{\circ} \mathrm{N}, 112.92977^{\circ} \mathrm{E}\right)$ 。为 研究这一强对流天气特征, 许多专家学者进行了分析, 汪小康 [1]等对 2015 
年 6 月 1 日江汉平原大暴雨过程进行诊断分析, 王晓芳[2]等对 2015 年 6 月 1 2 日长江流域灾害性天气灾情, 汛情和雨情特征进行研究, 郑永光[3]等对

“东方之星” 客轮翻沉事件周边区域风灾现场调查与多尺度特征分析, 以上 研究均没有对这一过程的闪电特征进行分析, 虽然国内外没有关于闪电对沉 船的影响分析, 但闪电可能造成轮船的电子设备损坏。本文利用当时闪电数 据和历年闪电资料进行分析, 揭示了监利县闪电的时空特征, 旨在通过这一 过程的闪电特征, 为雷电灾害调查提供分析依据。

\section{2. 资料来源于统计方法}

数据来源湖北省三维闪电定位系统, 采用 2015 年 6 月 1 2 日湖北省监测 到的闪电(包括云间闪、云地闪)资料, 统计分析正、负闪电次数及其所占闪 电总数的百分比; 云间闪、云地闪次数及其占闪电总数的百分比; 按照间隔 $10 \mathrm{kA}$ 一个区间, 把闪电强度 $\leq 200 \mathrm{kA}$ 的闪电按照 $0 \sim 10 \mathrm{kA} 、 10 \sim 20 \mathrm{kA}, \ldots$, 180 190 kA、190 200 kA(含左区间)进行统计, 分别统计各闪电强度段内的 闪电次数及占其闪电总数的百分比。在进行闪电的时间统计时, 按照整点时 段如 0 1 时、1 2 时, ..., 22 23 时、23 24 时(北京时间, 含左区间)统计每 小时内闪电次数滤除了电流大于 $300 \mathrm{kA}$ 的数据。用 2 天的日平均闪电次数 与监利县面积 $\left(\mathrm{km}^{2}\right)$ 之比得出该地区日平均闪电密度 (次 $/ \mathrm{km}^{2} \cdot \mathrm{d}$ )。

\section{3. 闪电实况}

本次天气过程全省第 1 次闪电发生在荆州石首市, 时间为 6 月 1 日 00:00:00, 最后 1 次闪电发生在咸宁的通城县, 时间为 6 月 2 日 23:48:16, 湖北省共发生 了 15255 次闪电, 其中正闪电 1919 次, 负闪电 13336 次, 负闪占全省总闪电 的 $87.4 \%$, 云闪 4186 次, 云地闪 11062 次, 云地闪占全省总闪电的 $72.5 \%$, 最大正闪电流 267.952(陡度 131.9), 最大负闪电流 283.591(陡度 181.5)。此过 程监利县共发生了 5089 次闪电, 其中正闪电 445 次, 负闪电 4644 次, 负闪 占全县总闪电的 $91.3 \%$, 云闪 1246 次, 云地闪 3843 次, 云地闪占全县总闪电 的 75.5\%, 最大正闪电流 237.973(陡度 145.1), 最大负闪电流 283.591(陡度 181.5)。

\section{4. 闪电时间分布特征}

从全湖北省逐小时闪电(见图 1) 可知, 该过程闪电频次的时间分布特征比较 明显, 最大值出现在 21 22 时, 全省 1 小时闪电达 2812 次, 监利县 1 小时闪 电达 1866 次, 占全省的 $66.4 \%$, 沉船事故点 $5 \mathrm{~km}$ 范围内 1 小时闪电达 183 次。从闪电时间变化曲线看, 从 20 时后闪电开始增加, 22 时闪电达到最大 值后开始减少。2 日 0 时后全省基本维持在 500 1200 次/小时,到 7 时后逐渐 消失, 监利县在 2 日 4 时后闪电基本消失, 沉船事故地点 $5 \mathrm{~km}$ 范围内 20 21 时有 10 次闪电, 21 22 时有 183 次闪电, 2 日 $0 \sim 1$ 时和 $1 \sim 2$ 时各 6 次闪电, 其他时段没有闪电发生。闪电次数增多与对流性加强呈正相关 [4], 这说明湖 北省从 1 日 20 时开始, 对流性雷电天气呈明显的上升趋势, 22 时开始减弱, 到 2 日上午 7 时后对流性雷电天气基本消失, 强对流性雷电天气主要集中在 1 日 20 时至 2 日 7 时, 监利县主要集中在 1 日 20 时 24 时, 最大出现在 21 


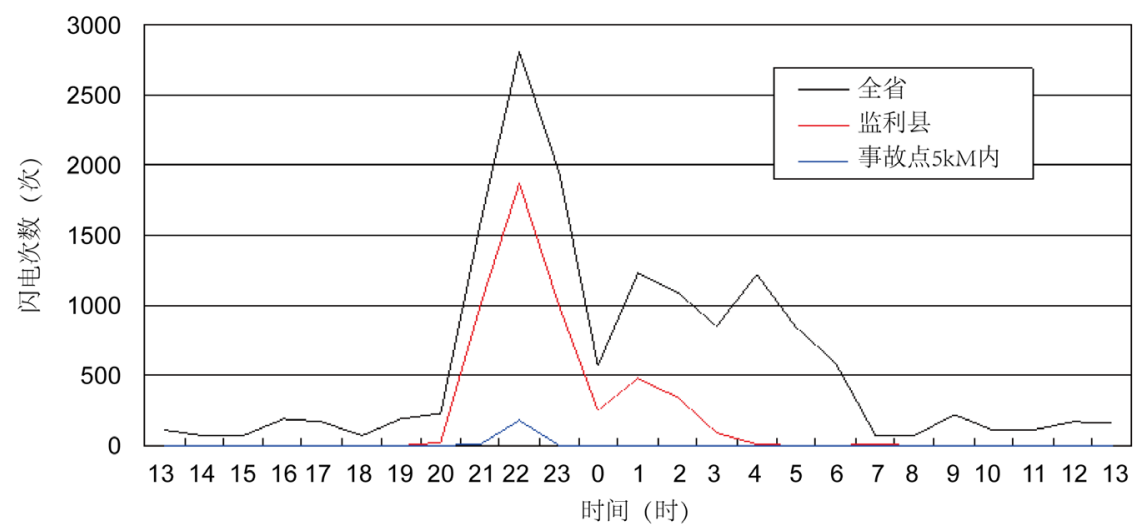

图 1. 2015 年 6 月 1 2 日湖北、监利县闪电时间分布图

时 22 时, 与沉船时间相吻合。从闪电实际分析发现, 在 20 时 39 分 27 秒前 有 16 次正闪和 1 次负闪, 间隔 7 分钟之后有 90 次负闪和 9 次正闪, 说明这 次强闪电由正闪为主转为负闪为主, 之后发生强烈的闪电过程。

\section{5. 闪电地域分布特征}

从图 2 可以看出, 全湖北省除鄂西北外全省均有闪电发生, 但主要集中在 江汉平原南部地区，其中洪湖市 1227 次、赤壁市 1788 次、崇阳县 1200 次、 华容县 1662 次、临湘市 2643 次、岳阳市区 2371 次、岳阳县 1608 次, 仅监 利县闪电 5089 次占全省总闪电数的 $33.4 \%, 2$ 天最大闪电密度位于监利县达 2.918 次 $/ \mathrm{km}^{2} \cdot \mathrm{d}, 1$ 日 20 22 时沉船事故地点 $5 \mathrm{~km}$ 范围内有闪电 193 次, $1 \mathrm{~km}$ 范围内有闪电 9 次, 均为负闪, 其中云闪 3 次, 云地闪 6 次, 从图 3 可以看 出, 离沉船事故地点闪电较多, 经计算最近距离一次闪电为 $263 \mathrm{~m}$, 发生在 21 时 26 分 09 秒, 闪电强度为 $-45.374 \mathrm{kA}$ 的云地闪, 由于闪电设备水平误差小 于 $300 \mathrm{~m}$ (站网内), 高度小于 $500 \mathrm{~m}$ (站网内), 轮船遭受雷击或船上通讯设备 受雷击电磁感应而损坏的可能性很大。

该过程前后 2 天全湖北省闪电很少, 分别为 15 次和 52 次, 也分散在全省 各地局部地区, 说明强对流性雷电天气过程是 6 月 1 日在该区域形成或加强, 经过 2 小时达到最强, 然后在该区域减弱逐渐消失, 整个强对流性雷电天气 过程位置变化不大，中心处于监利、洪湖、赤壁、崇阳、湖南岳阳之间的交 叉区域, 该区域闪电数量约 20000 次。这一过程虽然是当时切变线上的低浴、 低压倒槽等大气环流因子造成, 但在该特殊地形影响下得到加强[5]。该区域 地处江汉平原南部与东部山区交接过渡地带, 加之南有鄱阳湖, 北有洪湖, 又有长江水系交错, 土壤电阻率较低, 这种特殊地形的影响, 有利于云地间 闪电的发生, 也就是说在特殊地形影响下局部雷电天气较多, 且每次雷电天 气发生时强度大、持续时间较短[6]。

\section{6. 雷电流强度分布特征}

从闪电强度分布图(图 4)可知, 全省 0 100 $\mathrm{kA}$ 闪电有 14837 次, 占 $97.3 \%$, 10 40 kA 闪电有 10211 次, 占 $66.9 \%$, 也就是说全省闪电主要集中在 $100 \mathrm{kA}$ 以下, 一半以上是 10 40 kA 的闪电。监利县 10 100 kA 闪电有 4963 次, 占 $97.5 \%, 10 \sim 40 \mathrm{kA}$ 闪电有 3800 次, 占 $74.7 \%$, 说明监利县闪电主要集中在 10 


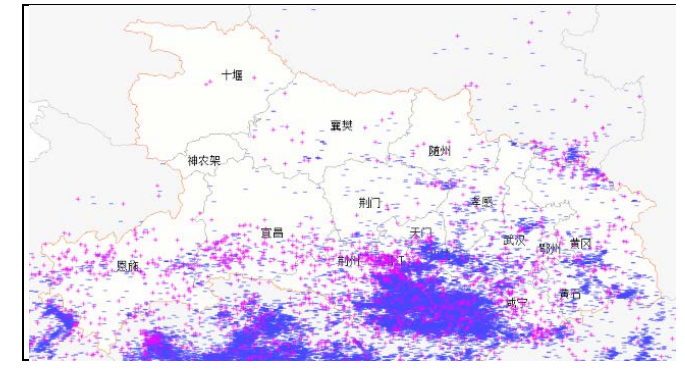

图 2.2015 年 6 月 1 2 日湖北闪电分布。（红色为正闪, 蓝色为负闪)

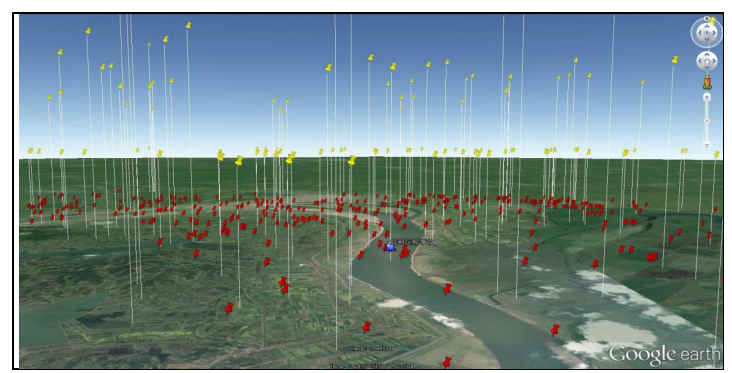

图 3. 2015 年 6 月 1 2 日事故点闪电三维分布。（黄色为云闪, 红色为云地闪）

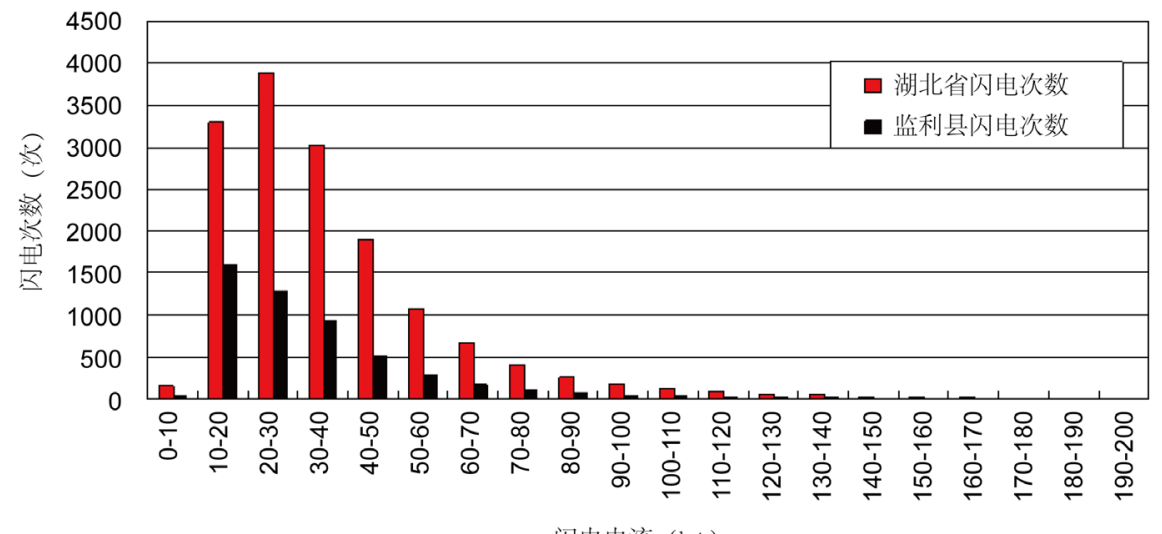

闪电电流 $(\mathrm{kA})$

图 4. 湖北省、监利县 6 月 1 2 日闪电强度分布图

$\sim 100 \mathrm{kA}$ 之间, 一大半以上是 10 40 kA 的闪电, 闪电电流更加集中, $10 \sim 20 \mathrm{kA}$ 闪电最多。因此, 在雷电防护规划方面应重点加强对此强度范围内的闪电的 防范和应对。

根据资料统计, 这一过程全湖北省共有 31 次 $200 \mathrm{kA}$ 以上电流的闪电, 其 中有 16 次发生在该区域, 全省最大的 7 次负闪中有 6 次均发生在监利县, 时 间主要在 21 时前后, 说明这次强闪电有一半集中在该区域; 在监利县闪电记 录中, $100 \mathrm{kA}$ 以上电流的闪电有 99 次, 时间集中在 19 时 42 分到次日 2 时 12 分这个时段。

\section{7. 结论与讨论}

2015 年 6 月 $1 \sim 2$ 日湖北省、监利县等地闪电资料统计表明:

1）湖北省负闪电占全省总闪电的 $87.4 \%$, 云地闪电占全省总闪电的 $72.5 \%$, 
监利县负闪电占全县总闪电的 $91.3 \%$, 云地闪占全县总闪电的 $75.5 \%$ 。

2) 湖北省和监利县闪电频次在 20 时后明显增加, 经 2 个时达到最高值后 开始减少, 再经过 2 时后进入相对平稳波动时段, 一直维持近 7 个小时后逐 渐消失, 强对流天气持续 4 小时, 时间特征明显。

3）闪电主要集中在监利、洪湖、赤壁、崇阳、湖南岳阳之间的交叉区域, 沉船事故地点 $5 \mathrm{~km}$ 范围内 2 小时闪电 193 次, 1 公里范围内 2 小时闪电 9 次, 最近距离一次闪电为 $263 \mathrm{~m}$ 。

4) 闪电强度在 $30 \mathrm{kA}$ 以下, 闪电频次随其强度的增加而迅速增加, 闪电频 次在 20 30 kA 时达最大值, $30 \mathrm{kA}$ 以上时, 闪电频次随其强度的减少而逐渐 减少, 要加强对 20 30 kA 强度范围闪电的防范。

5) 在监利县 $100 \mathrm{kA}$ 以上电流的闪电中, 占 $94 \%$ 的连续正闪转变到连续占 $91 \%$ 负闪现象, 可能是高频次闪电来临的前兆。

这次沉船事故发生在闪电频次最高时间段, 也是闪电频次最多的地域, 也 是负闪电电流最大的时间段和区域, 但不是发生最强正闪电电流的时间段和 地域, 这次闪电过程 10 40 kA 的闪电占 $74.7 \%$, 最近的一次闪电距离事故地 不足 $300 \mathrm{~m}$, 轮船遭受雷击或船上通讯设备受雷击电磁感应而损坏的可能性 很大, 需要进一步加强雷雨天气轮船安全防范。

\section{References}

[1] 汪小康, 廖移山. 2015 年 6 月 1 日江汉平原大暴雨过程诊断分析[J]. 暴雨灾害, 2015, 34(2): 184-190.

[2] 王晓芳, 徐明, 王婧羽, 等. 2015 年 6 月 1-2 日长江流域灾害性天气灾情, 汛情和 雨情特征[J]. 暴雨灾害, 2015, 34(2): 177-183.

[3] 郑永光, 田付友, 孟智勇, 等. “东方之星”客轮翻沉事件周边区域风灾现场调查与 多尺度特征分析 [J]. 气象, 2016, 42(1): 1-13.

[4] 周筠君, 郄秀书, 张义军, 等. 地闪与对流性天气系统中降水关系的分析 [J]. 气 象学报, 1999, 57(1): 103-111.

[5] 王羿, 周龙, 王洪祥, 等. 基于地形因子的水库区域闪电特征分析 [J]. 水电能源 科学, 2016, 34(4): 207-210.

[6] 张其林, 张源源, 李东帅, 等. 地形地表的不规则起伏对雷电电磁场传输的影响 [J]. 气象学报, 2013, 71(2): 357-365. 
Submit or recommend next manuscript to OALib Journal and we will provide best service for you:

- Publication frequency: Monthly

- 9 subject areas of science, technology and medicine

- Fair and rigorous peer-review system

- Fast publication process

- Article promotion in various social networking sites (LinkedIn, Facebook, Twitter, etc.)

- Maximum dissemination of your research work

Submit Your Paper Online: Click Here to Submit

Or Contact service@oalib.com 